\title{
Evaluation of the present status of academic family medicine in Taiwan
}

\author{
Kai-Kuen LEUNG and Ching-Yu CHEN \\ Department of Family Medicine, College of Medicine, National Taiwan University, Taipei, Taiwan
}

\begin{abstract}
Aim: To evaluate the status of academic family medicine in Taiwan in terms of the development of the Association of Family Medicine, family medicine residency programs, and continuing medical education programs.

Methods: A structured questionnaire was mailed to the chairs of the departments of family medicine in nine medical schools to collect information about faculties and family medicine curricula. Information about family medicine residency training programs, board certified family physicians, and continuing medical education (CME) programs were obtained from records of the Association of Family Medicine.

Results: There were 40 full-time family medicine faculties in nine medical schools. The largest group of them (40\%) are instructors. Professors were most productive in terms of research publication. All the medical schools have family medicine courses in their curriculum. Most of the lectures are given in the fifth year and practices begin in the sixth and seventh year of 7-year training for medical students. There were 65 family medicine residency training programs with 315 teaching staff in 2001. Most programs are small with only approximately four people on staff. The Taiwan Association of Family Medicine was founded in 1986. Shortly after its establishment, membership rose rapidly to 4993 by the end of 2001. The Taiwan board of family medicine was established in 1988. At the end of 2001, there were 4145 board certified family physicians in the country. The volume of CME delivered by Departments of Family Medicine reached its peak in 1992, and has gradually decreased to less than half of that number in 2000. However, opportunities for continuing education have been substituted by programs provided by others specialties.

Conclusions: Family medicine is a rapidly growing specialty in Taiwan. Past efforts have laid a concrete foundation for future development. Expansion of residency training and the improvement of academic achievements are important for the future development of our specialty.
\end{abstract}

(c) 2003 Blackwell Publishing Asia and Wonca

Key words: continuing medical education, curriculum, family medicine, training program.

\section{Introduction}

Taiwan is an island with a population of approximately 22 million people. There are 11 medical schools, which graduated approximately 1300 medical

Correspondence: Professor Ching-Yu Chen, Department of Family Medicine, College of Medicine, National Taiwan University, Taiwan.

Email: cychen@ha.mc.ntu.edu.tw

Accepted for publication 15 November 2002. students each year. Family medicine became an academic discipline approximately 20 years ago. General practice was originally the major source of medical care on this island. With the emergence of medical subspecialties, many physicians were trained as specialists and provided medical services in large hospitals instead of local communities. Medical services were unevenly distributed, resulting in an undersupply of medical services in many rural communities. Responding to the medical needs in our society, an experimental project to train family physicians and allocate them to rural areas was established in 1979. As part of this 
project, two family physicians were trained to provide medical services in a small village at the north east coast of Taiwan's main island. This project turned out to be very successful and opened the way for subsequent development of family medicine in Taiwan. The government began to fund family physician training programs in teaching hospitals beginning in 1985. With the incentives from the government, the progress of family medicine was rapid and fruitful. An academic association for family medicine was established in 1986. In 1989, family medicine was recognized as a medical specialty by the Department of Health. At the end of 2001, most of the 11 medical schools in Taiwan had a family medicine department that was responsible for family medicine education to undergraduate students. Family medicine departments and residency training programs were set up in many teaching hospitals to provide postgraduate training and continuing medical education (CME). After 20 years of hard work, family medicine has become a well established medical specialty. As an academic discipline, faculty development, undergraduate and residency programs, and scientific research are crucial for the growth of family medicine. In order to evaluate our efforts and to plan for the future, a country wide survey on family medicine curricula in medical schools was carried out in 2001. The status of the Association of Family Medicine, family medicine residency programs, and CME were reviewed. The results of these studies are analyzed in the present study.

\section{Materials and methods}

Data analyzed in this study came from two sources. A structured questionnaire was mailed to the chairs of the departments of family medicine in nine medical schools (two of Taiwan's 11 medical schools do not have family medicine departments). Questions asked included: (i) number, title, research interest, and publications of the faculty; and (ii) type of curriculum of the undergraduate family medicine courses. Informa- tion on family medicine residency training programs, board certified family physicians, and CME programs were obtained from records of the Association of Family Medicine. Frequency statistics and line charts were used to analyze the research data.

\section{Results}

\section{Undergraduate training in family medicine}

\section{(1) Faculty}

There are 40 full time family medicine faculties in the nine medical schools. Of this group, five (12.5\%) are professors, $14(35 \%)$ are associate professors, five $(12.5 \%)$ are assistant professors, and $16(40 \%)$ are instructors. Associate professors published the most research articles from 1998 to 2000. However, professors were most productive, with an average of 13.8 articles per person within 3 years (Table 1). Regarding the quality of publications, professors published an average of 8.4 articles in Science Citation Index journals within 3 years. Faculties of family medicine have a very wide range of research interest. Table 2 is a tabulation of research interest for family medicine authors. Family practice, community medicine, and preventive medicine were the top three research areas of the family medicine faculty.

\section{(2) Undergraduate family medicine training}

Table 3 shows the titles and characteristics of undergraduate family medicine curriculum in different medical schools. In Taiwan, medical training is a 7-year program including 1 year of internship in the final year. The first to fourth years focus on basic medical training and the fifth to seventh years concern clinical medical training. Most family medicine lectures are in the fifth year with practical courses in the sixth or seventh year. All the lectures are required and most of the practical courses are electives. In the National Taiwan University College of Medicine, all clinical courses are

Table 1 Publication pattern of family medicine faculties from 1998 to 2000

\begin{tabular}{|c|c|c|c|c|c|c|}
\hline \multirow[t]{2}{*}{ Title } & \multicolumn{3}{|c|}{ Research articles } & \multicolumn{3}{|c|}{ SCI articles } \\
\hline & Number & $\%$ & Average & Number & $\%$ & Average \\
\hline Professor & 69 & 19.6 & 13.8 & 42 & 30.7 & 8.4 \\
\hline Associate professor & 147 & 41.8 & 10.5 & 49 & 35.8 & 3.5 \\
\hline Assistant professor & 16 & 4.5 & 3.2 & 8 & 5.8 & 1.6 \\
\hline Instructor & 120 & 34.1 & 7.5 & 38 & 27.7 & 2.4 \\
\hline Total & 352 & 100.0 & & 137 & 100.0 & \\
\hline
\end{tabular}

Average, number of articles per person; SCI, Science Citation Index. 
Table 2 Research areas of family medicine faculties

\begin{tabular}{lcr}
\hline Research area & Number & \multicolumn{1}{c}{ \% } \\
\hline Family practice & 34 & 85.0 \\
Community medicine & 16 & 40.0 \\
Preventive medicine & 15 & 37.5 \\
Geriatrics & 9 & 22.5 \\
Medical education & 9 & 22.5 \\
Palliative medicine & 7 & 16.5 \\
Occupational medicine & 6 & 15.0 \\
Behavioral medicine & 6 & 15.0 \\
Adolescent medicine & 5 & 10.5 \\
Health management & 3 & 7.5 \\
Obesity & 3 & 7.5 \\
Medical informatics & 3 & 7.5 \\
Practice management & 3 & 7.5 \\
Women's health & 2 & 5.0 \\
Medical ethics & 1 & 2.5 \\
Travel medicine & 1 & 2.5 \\
Others & 3 & 7.5 \\
Total & 130 & 100.0 \\
\hline
\end{tabular}

†Rheumatology, nephrology, and epidemiology. (Research areas reported from family medicine faculties. Each faculty can report more than one area.) arranged in a rotation base. For family medicine courses, fifth year students are divided into six groups and rotated for a training of 6 weeks in an integrated course called 'Family, society and medicine'.

\section{(3) Family medicine residency programs}

There were 65 family medicine residency programs around the country in year 2001. A total of $66 \%$ of the programs were located in district hospitals (Table 4). Each training program must pass accreditation from the Association of Family Medicine before they can accept residents, and must receive reaccreditation every 3 years. A total of 315 teaching staff administer the 65 programs (Table 4). Although most of the staff work in district hospitals (52.7\%), medical centers have the largest staff in each program (an average of 7.9 on staff per program).

\section{(4) Family physicians and continuing medical education}

The Association of Family Medicine was founded in 1986. Shortly after being established, membership grew rapidly from 1986 to 1997; it has plateaued for the past 4 years. There were 4993 members at the end

Table 3 Family Medicine Curriculum in Taiwan Medical Schools

\begin{tabular}{|c|c|c|c|c|}
\hline Medical schools & Title of Teaching Programs & Duration & Type & Grade \\
\hline \multirow{3}{*}{$\begin{array}{l}\text { National Taiwan University College of } \\
\text { Medicine }\end{array}$} & Family, society, and medicine & 6 weeks & Compulsory & 5 \\
\hline & Family medicine practice (I) & 6 weeks & Elected & 6 \\
\hline & Family medicine practice (II) & 6 weeks & Elected & 7 \\
\hline \multirow[t]{3}{*}{ Kaohsiung Medical College } & Family medicine & 1 semester & Compulsory & 6 \\
\hline & Family medicine practice (I) & 3 weeks & Compulsory & 5,6 \\
\hline & Family medicine practice (II) & 2 weeks & Elected & 7 \\
\hline \multirow{3}{*}{$\begin{array}{l}\text { National Cheng Kung University College } \\
\text { of Medicine }\end{array}$} & Family medicine & 1 semester & Compulsory & 5 \\
\hline & Family medicine practice (I) & 3 weeks & Compulsory & 5 \\
\hline & Family medicine practice (II) & 2 weeks & Elected & 7 \\
\hline \multirow{4}{*}{$\begin{array}{l}\text { National Yang-Ming University College } \\
\text { of Medicine }\end{array}$} & Community medicine & 1 semester & Compulsory & 4 \\
\hline & Community medicine practice & 2 weeks & Compulsory & 4 \\
\hline & Family medicine practice (I) & 1 week & Compulsory & 6 \\
\hline & Family medicine practice (II) & 4 weeks & Elected & 7 \\
\hline \multirow[t]{3}{*}{ Taipei Medical College } & Family medicine & 1 semester & Compulsory & 5 \\
\hline & Family medicine practice (I) & 3 weeks & Compulsory & 6 \\
\hline & Family medicine practice (II) & 2 weeks & Elected & 7 \\
\hline \multirow[t]{2}{*}{ China Medical College } & Introduction to family medicine & 1 semester & Compulsory & 5 \\
\hline & Family medicine practice & 2 weeks & Elected & 6,7 \\
\hline \multirow[t]{2}{*}{ Chung Shan Medical and Dental College } & Family medicine & 1 semester & Compulsory & 6 \\
\hline & Family medicine practice & 4 weeks & Elected & 7 \\
\hline \multirow[t]{2}{*}{ National Defense Medical College } & Family medicine & 1 semester & Compulsory & 5 \\
\hline & Family medicine practice & 2 weeks & Elected & 6,7 \\
\hline \multirow[t]{3}{*}{ Buddhist Tzu Chi Medical College } & Family medicine & 1 semester & Compulsory & 5 \\
\hline & Family medicine practice (I) & 2 weeks & Compulsory & 6 \\
\hline & Family medicine practice (II) & 3 weeks & Elected & 7 \\
\hline
\end{tabular}


Table 4 Family medicine residency training programs in different levels of hospital (2001)

\begin{tabular}{lccccc}
\hline Type of hospital & \multicolumn{2}{c}{ Training programs } & \multicolumn{2}{c}{ Teaching staff } & Staff/program \\
& Number & \% & Number & \% & \\
\hline Medical center & 17 & 26.1 & 134 & 42.5 & 7.9 \\
District hospital & 43 & 66.2 & 166 & 52.7 & 3.9 \\
Community hospital & 5 & 7.7 & 15 & 4.8 & 3 \\
Total & 65 & 100.0 & 315 & 100.0 & 4.8 \\
\hline
\end{tabular}

Figure 1 Number of members of the Taiwan Association of Family Medicine and the number of board certified family physicians. $(-\downarrow-)$, number of members; (- - ), no of board certified family physicians.

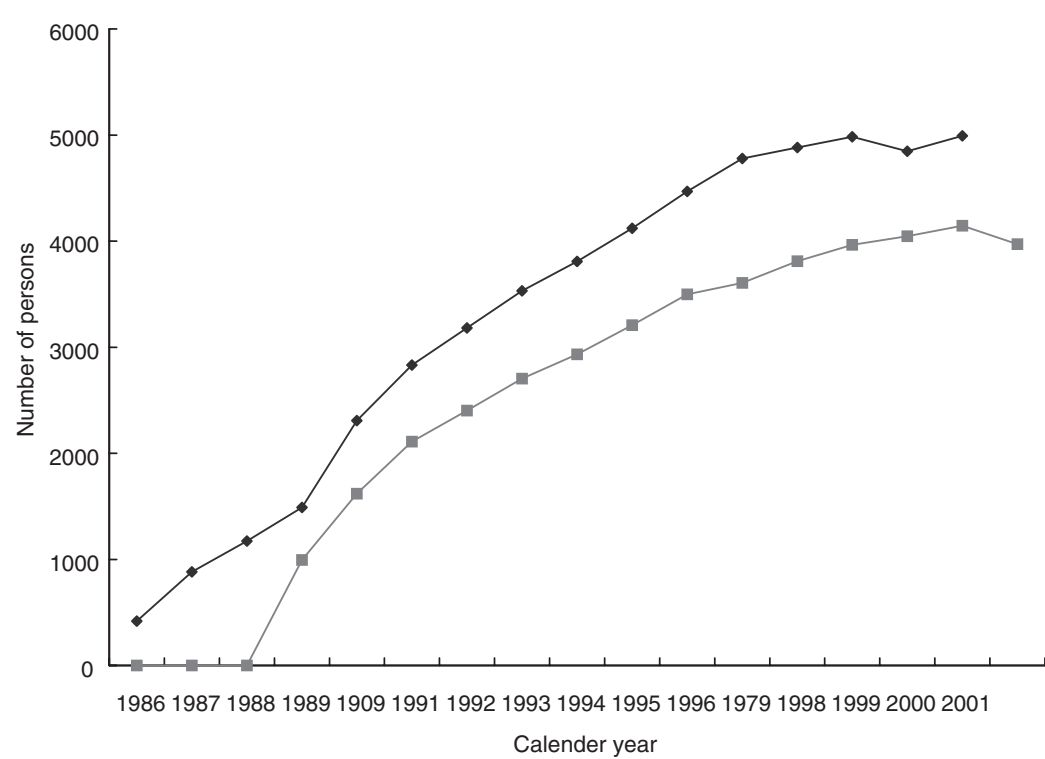

\section{Discussion}

Nine of the 11 medical schools in Taiwan have family medicine departments. Of the two medical schools without a family medicine department, one school was newly established 3 years ago so that many of its clinical departments were not fully set up by the time of the survey. The development of family medicine in medical schools benefitted from government policy. The presence of family medicine departments adds credits to the accreditation of medical schools. As a result, practically all medical schools should have family medicine departments in their structure. However, most family medicine departments are very small, with only an average of 4.5 faculty members in each department. The size of the department may constrain further development. According to our survey, family medicine is a required course in early clerkship, the fifth grade for medical students, in all medical schools. Information not shown in our quantitative data is that many family medicine faculties are also involved in many other courses such as medical informatics, medical ethics, geriatrics, and community medicine. This 


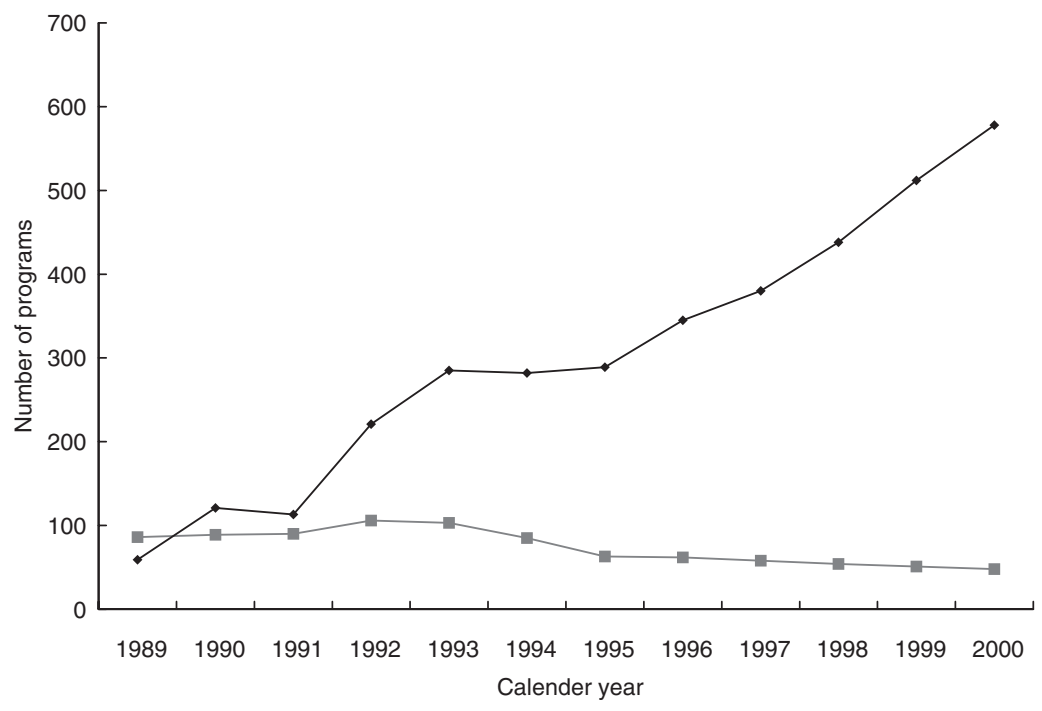

Figure 2 Continuing medical education (CME) programs from 1989 to 2000. (-ם-), family medicine CME; (- -$)$, CME provided by other specialties. wide involvement can be reflected on the diversity of research interests of the faculty members.

Compared to their colleagues in other clinical specialties, faculty members of family medicine departments were less productive in the quantity and quality of medical research. ${ }^{1}$ A study revealed a total of 101 articles written by family physicians published from 1979 to 1992 . Most of these studies were observational studies with a cross sectional study design. All research articles were contributed by 37 physicians. ${ }^{2}$ Although no one denies that academic research is important for the development of a specialty, there are many obstacles that prevent family physicians from doing medical research. A study of 115 family medicine faculties about the influencing factors on current research activity and productivity was conducted in 1997. Seventyone faculty members (61.7\%) were engaged in 124 research projects during the survey period. The only significant influence identified in the study was incompetence in research skills. ${ }^{3}$ As one article can be written by more than one author, there were repeated counting of articles in the present study because authors listed the number of articles independently. However, the quantity of medical research seemed to improve in recent years as more research articles have been published in the past 5 years than in the early 13 years. The number of articles published in SCI journals also reflect an improvement of quality of research. Nevertheless, the gap in academic achievements between family medicine and other clinical specialties is still present and continues to challenge the family medicine practice.

According to the regulations established by the association and approved by the Department of Health, the training capacity of a residency training program is limited by the number of teaching staff and facilities. In 2002, the total training capacity of all programs is 150 residents. Will the flux of family physicians meet the future needs of our country? A primary care physician manpower research study funded by the Department of Health is being carried out. We hope that such research provides some useful data upon which to develop future policy for family medicine residency training.

Continuing medical education credits are required in the certification and recertification by the family medicine board. This has created a huge demand for CME courses in the initial few years after the establishment of family medicine specialty. To meet the needs of family physicians, the number of CME courses increased rapidly. Since 1994, when other medical specialties began their board certification regulations, the number of family medicine specific CME courses markedly decreased to approximately half of its peak. We can explain this phenomenon in two parts. First, the demand of CME credits declined as most primary care physicians in the practice have already received board certification. Second, many other medical specialties began their own CME courses and credits offered by other medical specialty programs are normally accepted by the Association of Family Medicine after review. The higher number of CME courses in the academic medical society eased the pressure of the family medicine association to provide more CME courses for its members and the association can refocus its attention to other academic and educational missions. Although CME is a common tool to update medical knowledge for practicing physicians, its effectiveness in changing physicians' practicing behavior has not been observed. ${ }^{4,5}$ Other educational strategies should be developed and evaluated for the continuing education of family physicians. 


\section{References}

1 Cluff LE. A research agenda for family physicians. J. Fam. Pract. 1984; 18: 145-8.

2 Lee MC, Fu CC, Chen PH, Chou MC. Analysis of published papers on family medicine in Taiwan from 1979 through 1992. Chin. J. Fam. Med. 1994; 4: 51-61.

3 Fu CC, Lee MC, Chen JD, Chiou JY, Tai TY. Influencing factors on research activity and productivity of faculties of family medicine residency programs in Taiwan. Chin. J. Fam. Med. 1997; 7: 1-12.

4 Davis D. Does CME work? An analysis of the effect of educational activities on physician performance or health care outcomes. Int. J. Psychiatry Med. 1998; 28: 2139.

5 Brigley S, Young Y, Littlejohns P, McEwen J. Continuing education for medical professionals: a reflective model. Postgrad. Med. J. 1997; 73: 23-6. 